\title{
Escola Polivalente de Osório-RS: Políticas Educacionais e Trabalho a partir da História Oral
}

\section{Polyvalent School in Osório City - RS: Educational Policies and Work from the Oral History}

\author{
Maria Augusta Martiarena de Oliveira \\ Orcid: https://orcid.org/0000-0002-1118-3573 \\ Instituto Federal de Educação, Ciência e Tecnologia do Rio Grande do Sul, Osório, \\ Brasil, augusta.martiarena@osorio.ifrs.edu.br \\ Valesca Brasil Costa \\ Orcid: http://orcid.org/0000-0002-3679-0273 \\ Faculdade de Direito - JPII, Pelotas, Brasil, valescacosta@hotmail.com
}

Received on 07/05/2020 - Approved on 10/05/2020

\section{Resumo}

Este estudo refere-se à Escola Maria Teresa Vilanova Castilhos - Escola Polivalente, de Osório, Rio Grande do Sul, cuja fundação ocorreu em 1974, no bojo dos acordos MEC-USAID. Quanto à metodologia, o presente estudo desenvolve-se a partir da História Oral, tendo-se realizado quatro entrevistas, com docentes que atuaram na referida instituição. O objetivo do presente estudo é analisar como as políticas públicas em educação influenciavam nas práticas que se desenvolviam no âmbito escolar, bem como da forma como compreendiam a formação técnica em nível de 1. grau e sua relação com as disciplinas da base comum. Este estudo viabiliza perceber como os atores cotidianos refletem e ressignificam na esfera escolar as concepções de ensino integrado e de formação humana integral.

Palavras-chave: Escolas polivalentes. História Oral. Políticas Públicas em Educação.

\begin{abstract}
This study refers to the Maria Teresa Vilanova Castilhos School - Escola Polivalente, from Osório, Rio Grande do Sul, whose foundation took place in 1974, without any connection with MEC-USAID. As for the methodology, the present study was developed from Oral History, having been carried out four interviews, with professors who worked at the institution. The objective of the present study is to analyze how public policies in education influence the practices they develop in school education, as well as how to understand technical training at the 1st level and its relationship with the common base subjects. This study makes it possible to perceive how the
\end{abstract}


everyday actors reflect and reframe the concepts of integrated teaching and integral human formation in the school sphere.

Keywords: Polyvalent Schools. Oral History. Public Policies in Education.

\title{
Introdução
}

A pesquisa em história das instituições educacionais constitui-se em campo muito abrangente da História da Educação. Este estudo refere-se à Escola Maria Teresa Vilanova Castilhos - Escola Polivalente, de Osório, Rio Grande do Sul, cuja fundação ocorreu em 1974, no bojo dos acordos MEC-USAID. Tal instituição constitui-se em objeto de pesquisa ao longo de uma trajetória de investigação iniciada em 2012, com o projeto "Acervos Escolares: as instituições educacionais de Osório". Como afirma o renomado historiador da educação, Justino Magalhães:

\begin{abstract}
A escola é tema recorrente da história da educação. Abordada sob diversas perspectivas de informação e análise, a historiografia da escola vem sendo ampliada e renovada. Nos últimos anos, multiplicaram-se os olhares sobre a especificidade (cultura escolar, pedagogia, arquitectura, mobiliário, materiais didácticos, artefactos, disposição espacial); diversificaram-se estudos comparativos de amplitude territorial (local, regional, nacional, federal); foram revigorados parâmetros e perspectivas sobre mundialização e globalização do processo e do modelo pedagógico-didáctico escolares", (Magalhães, 2010, p.33).
\end{abstract}

Como menciona o autor, escola é tema usual na História da Educação, entretanto, pode ser analisada a partir de diferentes perspectivas. Optou-se por estudar a Escola Polivalente e alguns motivos em particular levaram a isso. Em primeiro lugar, o Instituto Federal de Educação, Ciência e Tecnologia do Rio Grande do Sul é uma instituição de educação profissional. Fazia muito sentido realizar, então, uma investigação sobre uma escola criada para oferecer, também, uma formação profissional.

A História da Educação Profissional ainda é um campo com relativamente poucas produções nessa área, notadamente se comparada com outros temas. $O$ seu estudo é extremamente relevante, inclusive no que tange à compreensão do papel e da missão dos lfs. Existe uma série de elementos que perpetram a história da educação brasileira, os quais definem espaços e funções determinadas para cada nível e/ou modalidades de ensino. Nesse sentido, é fundamental pensar no que afirma Maria Ciavatta, referência nos estudos de Educação Profissional e Educação e Trabalho:

A educação, no Brasil, tem acompanhado a divisão social do trabalho que separa os que pensam dos que executam, atribuindo a cada classe de trabalhadores remuneração e lugares sociais diferentes. A história da educação brasileira tem um tema recorrente, a separação entre a cultura da escola, a cultura geral e a cultura do trabalho, a formação profissional para o mercado de trabalho, para a produção, o produtivismo e a competição sem limites - hoje mais grave, diante da mundialização do capital, (Ciavatta, 2007, p. 15).

$\mathrm{Na}$ encruzilhada entre a história das instituições educacionais e os estudos de educação e trabalho, o presente estudo objetiva analisar como as políticas públicas em educação influenciavam nas práticas que se desenvolviam no âmbito escolar, bem como da forma como compreendiam a formação técnica em nível de 1.․ grau e sua relação com as 
disciplinas da base comum. Para tanto, inicia-se com uma breve explanação sobre a fundação da Escola Polivalente. Em seguida, apresenta-se os referenciais teóricometodológicos que pautaram o uso da História Oral. Posteriormente, apresenta-se a fundamentação referente às relações entre as políticas públicas e o cotidiano escolar. Por fim, a partir das memórias dos docentes, analisa-se como se deu a relação entre as políticas e as práticas ocorridas no âmbito da escola estudada.

\section{A fundação da Escola Polivalente de Osório}

Como mencionado anteriormente, a Escola Maria Teresa Vilanova Castilhos Polivalente foi fundada no âmbito dos acordos entre o Ministério da Educação e da Cultura e a Agência Internacional para o Desenvolvimento (USAID). Essa agência contratou quatro especialistas, os quais atuaram como consultores por dois anos, em conjunto com quatro educadores brasileiros. Esse grupo constituiu a equipe responsável por implementar as ações previstas pelo convênio, estruturando-se a EPEM (Equipe de Planejamento do Ensino Médio) nacional, constituída de oito membros. O acordo inicialmente previa uma duração de dois anos (31/03/65 a $30 / 07 / 67$ ), entretanto foi renovado e vigorou até 1976, atendendo principalmente os estados do Rio Grande do Sul, Minas Gerais, Espírito Santo, Bahia e Pernambuco.

A Escola Polivalente de Osório foi inaugurada no dia 14 de novembro de 1974 e vinculava-se à proposta educacional proveniente das relações entre o MEC e a USAID, notadamente no que tange às aptidões e a preparação para o trabalho. Assim como as outras escolas da rede, a sua implantação contou com grandes recursos, os quais envolviam as esferas nacional, estadual e municipal. Destaca-se que as Escolas Polivalentes diferenciavam-se pela oferta das disciplinas técnicas em conjunto com disciplinas da base comum. Eram oferecidas: técnicas industriais, técnicas agrícolas, técnicas comerciais e técnicas domésticas.

Em 1975, a escola contava com 640 alunos. Ao integrar uma rede, deve-se ter em conta que a instituição atendia e reproduzia uma série de valores, concepções e intencionalidades. Entretanto, a implantação em diferentes regiões do país, inevitavelmente levou a uma apropriação diferenciada conforme o local em que a escola era instalada. Desta forma, este trabalho objetiva analisar como as políticas públicas em educação influenciavam nas práticas que se desenvolviam no âmbito escolar, bem como da forma como compreendiam a formação técnica em nível de $1 .$. grau e sua relação com as disciplinas da base comum.

Com relação à criação da Escola Polivalente de Osório, Martiarena de Oliveira (2017) afirma que a implantação dessa rede de escolas foi um empreendimento que envolveu muitos recursos e instituições diferentes, além de envolver as esferas nacional, estadual e municipal. Segundo a autora, a inversão de recursos em sua construção gerou frutos notadamente em sua estrutura física, pois a instituição contava com amplas salas de aula convencionais, além de salas de aula específicas para cada disciplina técnica, uma biblioteca, além de grande estrutura externa, com campo de futebol, quadras poliesportivas de concreto e areia, pista de corrida e de salto em distância. Destaca-se que a inclusão de disciplinas técnicas no currículo (técnicas industriais, técnicas comerciais, técnicas agrícolas e técnicas domésticas), era considerada um diferencial e encontrava-se em consonância com o que afirmou Araújo (2010) sobre a relação entre assistencialismo e atendimento ao mercado. 
Entretanto, ainda que as Escolas Polivalentes tenham sido criadas para configurarem-se em propaganda do regime militar e, conforme Souza e Lima (2016), viabilizar a entrada antecipada de jovens no mercado de trabalho, a sua estrutura ampla e organizada, bem como a circulação de docentes que propiciou, atuaram no sentido de manutenção dos estudantes na escola e na vida escolar. Deve-se ter em conta que a história das instituições escolares estão marcadas pelas políticas públicas, mas, também, pela atuação dos sujeitos integrantes da comunidade escolar.

\section{História Oral e pesquisa documental: referenciais teórico- metodológicos}

Quanto à metodologia, o presente estudo desenvolve-se a partir da História Oral, o que durante muito tempo foi contestado por parte dos pesquisadores quanto ao uso da História Oral nas pesquisas. Entretanto é preciso que se destaque eu quando se fala em História Oral há uma relação direta com a memória, assim antes é interessante fazer brevemente uma abordagem sobre a memória.

Os Gregos muito se utilizaram da memória e da história oral para preservar e revisitar sua história, em especial através da figura do "mito grego", a veracidade ou não dos fatos narrados provavelmente até hoje não se terá como comprovar, entretanto foi fundamental para o povo Grego e para o Ocidente. A memória tem para as pessoas como maneira de manter sempre viva sua história de vida, desde os gregos que há muito tempo já perceberam ao instituir à Deusa Mnemosyne (mãe das musas que protegem as Artes e História) suas obras através de registros tornarse memoráveis, não morrendo jamais.

É preciso que se destaque que será no século $X X$ que a memória passará a ser importante objeto de reflexão nas ciências humanas, assim, a análise das memórias individuais e coletivas.

Assim, o uso difundido da expressão "História Oral", tanto quanto do gravador, tem contribuído para elaboração de uma nova escrita da história; no caso dessa pesquisa, assim como metodologia de pesquisa a História Oral:

[...] não é um fim em si mesma, e sim um meio de conhecimento. Ela não encerra um estatuto fechado, que permite justificar 'a história oral pela história oral'. Ao contrário: seu emprego só se justifica no contexto de uma investigação cientifica, o que pressupõe sua articulação com um projeto de pesquisa previamente definido (Alberti, 1989, p. 12).

Logo, apesar dessa contestação, destaca-se que a História Oral ganhou espaço nas pesquisas visibilizando a voz especialmente daqueles sujeitos que durante muito tempo ficaram à margem dos estudos históricos, como mulheres, crianças, idosos. Como ressaltam Grazziotin e Almeida (2012, p. 36):

O trabalho com História Oral exige conhecimento de quem se propõe a fazê-lo. Soma-se a isso, cumplicidade, escuta sensível e respeito à fala do outro. A História Oral é um dos meios que promovem aproximações entre História e Memória. 
Dessa maneira, possibilita que, através de suas falas, seja possível revisitar importantes momentos da história, mas que, pelo espaço de não protagonismo destes sujeitos, ficaram durante muito tempo silenciados. Quando tratamos de história oral estamos trabalhando diretamente com uma noção de memória, pois de nada é a narrativa oral sem o sustento da memória. Como adequadamente lembra Thompson, toda a fonte histórica derivada da percepção humana é subjetiva, "mas apenas a fonte oral permite-nos desafiar essa subjetividade: descolar camadas de memória, cavar fundo em suas sombras, na expectativa de atingir a verdade oculta" (1992, p. 197).

Ainda quanto à História Oral, esta pesquisa esta amparada em autores que nos permitem ter como base o uso de entrevistas com sujeitos que participaram deste momento à que o recorte temporal deste trabalho se dedica. Cabe ainda considerar que serão entrevistados um total de 4 pessoas, tendo como mote principal, ao aplicar as entrevistas, os questionamentos de quais as influências das políticas públicas em educação nas práticas pedagógicas e na identidade institucional local.

A História Oral se materializa nas entrevistas e no contato direto com o pesquisado se elucidam os fatos da melhor maneira possível, bem como se pode indagar e ir mais a fundo em determinado ponto ou esclarecer melhor fatos, tudo isto com a finalidade de registrá-los para preservar o passado, como bem considera Amado (1995, p. 134):

\begin{abstract}
Penso que entrevistas podem e devem ser utilizadas por historiadores como fontes de informações. Tratadas como qualquer documento histórico, submetidas contraprovas e análises, fornecem pistas e informações preciosas, muitas inéditas, impossíveis de serem obtidas de outro modo.
\end{abstract}

É preciso destacar que no momento da entrevista há entre entrevistado e entrevistador certa cumplicidade, pois as memórias dos entrevistados serão de certa maneira despidas. Assim, é preciso que se considere que o papel do pesquisador não é só procurar expor as memórias do entrevistado, mas deve ir além; precisa ser solidário naquele momento que, para muitos, não tem muita importância, contudo para quem trabalha com história oral pode ser momento fundamental.

Com isso é interessante que o pesquisador busque em conversa preliminar com o entrevistado demonstrar o quanto é valiosa sua entrevista, e que ao contrário do que muitos alegavam, revisitar sua memória e contar sua história é muito importante, conforme bem observado por Thomson (1997, p. 59):

\footnotetext{
Alguns deles resistiam ao meu questionamento temático... Outros recebiam bem as novas perguntas e a oportunidade de discutir e recordar de uma forma diferente. Meu interesse e minhas perguntas sugeriam que aspectos de sua vida- sobre os quais antes talvez tivesse sido difícil falar- eram de importância histórica e, em certos casos ajudavam a reafirmar o valor daquelas lembranças.
}

Ainda quanto à metodologia, é fundamental destacar que as entrevistas serão realizadas a partir da aplicação de questionário, pois se trata de uma entrevista semiestruturada, a qual conta com determinadas perguntas previamente organizadas, mas abre espaço para acréscimos de elementos que os sujeitos julgarem relevantes abordar. 
$\mathrm{Na}$ sequência, as mesmas serão gravadas para, na sequência, serem degravadas e/ou transcritas. Posteriormente serão analisadas as falas dos 4 sujeitos estudados e destacando o que fora mencionado e que se refere ao contexto estudado neste trabalho.

O momento da entrevista cria espaço para o entrevistado expor suas memórias, material que será chave para a elaboração do trabalho pesquisado. Nesse momento toda a habilidade do entrevistador é pouca para captar o máximo de informação para seu trabalho Detalhes imprescindíveis no momento da gravação, como ressalta Verena Alberti (2005, p. 114):

Durante a gravação de uma entrevista, é preciso destinar o máximo de atenção ao entrevistado, não só pela importância do que ele diz, mas também porque essa clara demonstração de interesse concorre para que se sinta estimulado a falar. Uma entrevista de história oral constitui uma reflexão e recuperação do passado levada a efeito ao longo de uma conversa.

Cabe destacar que, como mencionado anteriormente, antes da realização das entrevistas, será definido um breve roteiro de perguntas, buscando antes das entrevistas traçar um contexto lógico das questões que serão aplicadas aos sujeitos selecionados, buscando mapear os fatos históricos contextualizados naquele momento e relacionar com a fala dos sujeitos.

Quanto ao questionário, este tem o objetivo melhor proporcionar o estudo do conteúdo das falas captadas nas entrevistas, proporcionando que melhor se mapeie o conteúdo à que esta pesquisa se propõe. Além disso, procura-se perceber como educação e trabalho eram entendidos pelo corpo docente, notadamente a partir da concepção de formação profissional em nível de 1.ำ grau.

É preciso que se destaque que para esta pesquisa em especial, que se registre que para selecionar os sujeitos que seriam posteriormente estudados, os sujeitos entrevistados foram identificados e localizados a partir de um periódico pedagógico produzido por docentes da instituição, denominada Revista Polivisão. A partir da análise e organização dos textos publicados, promoveu-se a identificação dos autores, bem como o traçado de relação dos mesmos com a escola e com a docência.

Quanto à seleção dos sujeitos entrevistados é preciso que se destaque que tal periódico constitui-se em relevante documento para o estudo da história da educação osoriense. Ainda que não seja o objeto deste estudo, foi base importante para a definição dos entrevistados. Entre os mesmos, encontram-se pessoas que atuaram tanto na docência das disciplinas técnicas, como na gestão e na supervisão escolar.

Tendo em vista a intrínseca relação entre a referida rede e o Regime Militar, pretende-se, ainda, compreender se a forma como as práticas educacionais ocorriam eram pautadas pelas diretrizes educacionais ou se havia a confluência de outras teorias pedagógicas. No que se refere à bibliografia usada como base nos estudos, este trabalho se ampara em autores como Ferreira (1996), Alberti (2005) quando abordado sobre História Oral. Ainda na bibliografia, faz uso de autores como Shiroma (2011), Araújo (2010) e Souza e Lima (2016) no que se refere à Política Pública de Educação e às Escolas Polivalentes. 


\title{
As políticas públicas e o cotidiano escolar
}

Ainda no inicio deste trabalho, quando as bases teóricas estavam sendo construídas não se pretendia abordar à respeito das políticas publicas, e mais especificamente das políticas publicas de educação.

Entretanto, ao aprofundar a pesquisa se observou que as políticas publicas de educação foram instrumentos fundamentais para que o Estado neste período não só agisse na questão educacional. É justamente por isto que este capítulo se dedica a estudar justamente a presença das políticas públicas no cotidiano escolar.

$\mathrm{Na}$ Filosofia, Aristóteles considerava que o ser humano é uma animal racional e político, e em sua obra intitulada "A Política" já observava que a "Pólis", "cidade-Estado" tinha uma função fundamental na realização plena do homem como animal dotado de razão e como seu cidadão, como se observa abaixo:

\begin{abstract}
Sabemos que toda cidade é uma espécie de associação, e que toda associação se forma tendo por alvo algum bem; porque o homem só trabalha pelo que ele tem conta de um bem. Todas as sociedades, pois, se presupõem qualquer lucro - sobretudo a mais importante delas, pois que visa a um bem maior, envolvendo todas as demais: a cidade ou sociedade política. (Aristóteles, 2017, p. 17).
\end{abstract}

Assim, antes de nos determos a analisar mais especificamente as políticas publicas de educação, é preciso I que se tenha a noção do que é política pública representa um instrumento de ação do Estado. Desta feita, ainda que o termo "política" possa ter muitos significados, quando se trata de política pública, e mais especificamente de política pública de educação é um instrumento de ação do Estado, ou seja, as mãos do Estado em ação direta ao cidadão.

O uso corrente do termo 'Política' prenuncia uma multiplicidade de significados, presentes nas múltiplas fases históricas do Ocidente. Em sua acepção clássica, deriva de uma adjetivo originado de polis - politikós- e refere-se a tudo que diz respeito à cidade e por conseguinte, ao urbano, civil, público, social. (Shiroma et al., 2004, p. 8)

A entrada tardia brasileira no Capitalismo, e considerando os Estados Unidos da América como um país que teria o modo de produção dito como certo, iria impor aos governantes daquele momento consideraram seguir os passos deste país. Assim, implementou no campo da educação uma política baseada no que foi aplicado no governo norte americano, não só ao que se refere à economia como à educação.

Assim, esta entrada tardia do Brasil no sistema Capitalista e consequentemente no modelo industrial esta intimamente relacionado com a dependência neste momento das orientações dos Estados Unidos da América do Norte, de maneira que fica nítido esta situação ao se firmar o tratado MEC- USAID, impondo a educação tecnicista no Brasil.

\section{Políticas, educação e trabalho na Escola Polivalente}


Ao pensar a história das instituições educacionais, deve-se ter em conta o que afirma Magalhães (2010, p.33): "A teoria da escola como objecto historiográfico estrutura-se em duas constelações factoriais: a da cultura escrita e das práticas pedagógico-didácticas. Essas constelações desenvolveram-se agregadas e contextualizadas na instituição educativa, sendo actualizadas pela cultura escolar". O presente estudo debruçou-se sobre a análise de como as políticas educacionais interferem nas práticas pedagógico-didáticas.

Para compreendê-las, levou-se em consideração outra afirmação do já mencionado historiador da educação: "As principais fontes de informação sobre a escola respeitam a três áreas: a materialidade; a organização e a acção pedagógicodidactica; vivências e memórias", (Magalhães, 2010, p. 23). Ainda que ao longo do projeto de pesquisa em que o presente estudo insere-se tenha-se abordado fontes documentais 1 , as quais se constituem como elementos de materialidade, neste momento, optou-se por utilizar as memórias como objeto principal. O presente estudo desenvolveu-se, portanto, a partir das entrevistas de três sujeitos, os quais atuaram como docentes na Escola Polivalente entre as décadas de 1970 e 1990. São eles: Naura Martins, que será identificada como NM; Teresinha Walker, identificada como T.W. e Sebastião Fich da Rosa, identificado como S.F.R.

Nascido como uma política de governo, institucionalizada durante a Ditadura Civil-Militar, a Escola Polivalente de Osório foi recebida com grande receptividade na cidade. Conforme NM, entrevistada no dia 06 de maio de 2019, professora aposentada da rede estadual do Rio Grande do Sul e atualmente docente na rede privada no Ensino Superior:

\begin{abstract}
A Escola Polivalente é... eu a conheço desde o tempo em que foi inaugurada, meus irmãos estudavam lá, né... tinha todo uma característica, tinha toda uma filosofia própria. E sempre a gente acompanha o que o nacional e que o estado determinam, então era uma escola respeitadíssima, os alunos muito comprometidos, né.. muito orgulhosos de pertencerem à escola, né... (NM, entrevista, 2019).
\end{abstract}

A entrevistada atuou como docente na Escola entre 1984 e 1989 e considera que a Escola Polivalente criou uma identidade própria, pois, em suas origens, contava com toda uma organização curricular que envolvia 0 aluno, tanto nas disciplinas, quanto na parte prática, vinculada às técnicas, então o aluno ali tinha muito aprendizado prático, aliado ao teórico. As afirmações de Naura Martins, encontram-se em consonância com os apontamentos realizados por Teresinha Walker, professora na Escola Polivalente entre 1980 e 1998, a qual afirma:

\begin{abstract}
Eles (alunos) amavam as técnicas agrícolas. Era uma maravilha. Eles levavam hortaliças para a casa, cuidavam, depois da aula iam correndo para molhar. Eles tiravam o inço (?) dos canteiros. Eles tinham os seus canteiros, era uma coisa. Depois tinha uma estufa que era coisa rara naquela época. O Rovides (?) era o mais cabeça, o professor Rovides. Até com Educação Física havia bastante integração. E as técnicas industriais era maravilhoso, eles faziam trabalhos maravilhosos, chegavam a dar para a gente [...] (TW, entrevista, 2019).
\end{abstract}

A professora Teresinha Wlaker continua: "A gente achava ótimo, maravilhoso. Era vibrante ver como eles gostavam, quer ver as domésticas que eles aprendiam a fazer tudo quanto é tipo de comida, né... a parte de estética também. E eles 
contavam para nós, era muito gratificante, eles sentiam um amor grande pela escola" (TW, entrevista, 2019). O sentimento de nostalgia com relação aos primeiros anos da instituição referem-se ao fato de que a história da educação e do trabalho não se dão separadamente da história pessoal de seus agentes, de seus atores. Nesse sentido, Ciavatta (2007, p. 34): "O tempo da memória é social, não só porque o calendário é da festa, do evento político e do fato insólito, mas também porque repercute no modo de lembrar. A história contada do trabalho e da educação é, antes de tudo, a história da vida das pessoas."

O professor Sebastião Fich da Rosa, também um dos entrevistados, formouse pela UFRGS, em que $90 \%$ do curso eram matérias da Agronomia e o restante, matérias pedagógicas. Tornou-se professor para lecionar tanto para 1.ำ como 2.0 graus. Foi professor da Escola Polivalente entre 1975 e 1981, na qual foi docente e diretor. Enquanto diretor, propiciou a vinda de palestrantes da UFRGS, da PUCRS e de outras instituições para abordar temas pedagógicos. No final de 1981, transferiuse para a Escola Rural (Escola Ildefonso Simões Lopes), também em Osório - RS. Conforme o docente:

Quando a gente fez o curso de Educação, eles incentivaram muito o processo experimental, ou seja, tu pegar uma ideia, levantar hipóteses sobre ela, desenvolver um experimento, fazer um estudo, um debate científico, uma discussão como é chamada, e depois se chegar a uma conclusão. Isso fizemos nós na faculdade e viemos com essa ideia para fazer com os alunos. (SFR, entrevista, 2019).

Em conjunto com o professor Vicário, o referido docente entendeu que o melhor laboratório para o desenvolvimento de plantas seria o espaço externo. Criouse, então, o campo experimental de técnicas agrícolas, o qual objetivava a realização de experimentos nos quais os alunos pudessem levantar hipóteses, desenvolver a partir da experimentação. Nesse sentido, percebe-se que as disciplinas técnicas, originalmente idealizadas para formar mão de obra pouco onerosa para atender o mercado de trabalho, acabaram para se constituir em espaços de formação de um pensamento lógico.

Todos os entrevistados acima citados mencionaram a leitura de obras de Paulo Freire, as quais influenciaram suas práticas pedagógicas. Deve-se ter em conta que a teoria freireana contrapunha-se às propostas tecnicistas presentes nas políticas educacionais propostas durante a Ditadura Civil-Militar. Percebe-se, então, que ocorreu uma ressignificação das políticas educacionais no âmbito da escola. Assim, entende-se que:

São as relações, tensões e conflitos entre as mudanças conjunturais e a materialidade estrutural de uma determinada sociedade o tecido social que nos permite apreender, de forma dialética, o sentido e a natureza das alterações das políticas e práticas sociais, do trabalho e da educação, das relações e das condições do trabalho em um determinado momento histórico. Assistimos a várias mudanças conjunturais que não afetam a estrutura de desigualdade que dá forma de ser à população, (CIAVATTA, 2015, p.35).

\section{Considerações finais}


No caso deste estudo é fundamental destacar que concomitante aos desejos políticos do momento, o país elaborou uma Política Pública de Educação voltada à satisfazer os interesses que corroborassem com o exercício do tratado MEC-USAID. Desta feita é fundamental destacar que corroborando com o tratado MEC-USAID, a política pública de educação deste período, buscava especialmente que o ensino fosse focado especialmente em um conteúdo tecnicista, ou seja, buscava centrar o conhecimento dos alunos em um ensino que privilegiava as disciplinas técnicas, visto que buscava mão de obra técnica para a entrada imediata no mercado de trabalho e não primava pela formação de conhecimentos nas áreas das ciências humanas.

É preciso ainda que se destaque, que é através de políticas públicas de educação que o Estado tem sua ação através da elaboração legal e de manejo orçamentário às ações que se referem à educação à população, assim, se percebe que as atividades dentro das escolas estão intimamente direcionadas pelas políticas públicas de educação elaboradas pelo Estado, o que não seria diferente nesta pesquisa em questão, em que através de convênio com outro país buscava oferecer a parte da população brasileira uma educação tecnicista. Entretanto, as práticas que se levaram a cabo no âmbito da instituição estudada, nem sempre estiveram em consonância com os anseios do regime vigente.

Essa investigação viabiliza entender como os pequenos (por desconhecidos, mas grandes pelo seu papel de ação transformadora no cotidiano escolar) refletem, ressignificam e levam ao dia a dia da escola em uma pequena cidade do litoral norte gaúcho, as concepções de ensino integrado e de formação humana integral. É mister destacar, que após transcritas as entrevistas e feitas a respectivas analises dos material, emergem nas falas dos sujeitos entrevistados conteúdos que mostravam justamente um movimento que apesar das orientações das políticas públicas de educação do momento à que se propõe este recorte temporal, se opõe à estas imposições vinda de cima para baixo resultado do tratado MEC-USAID, ou seja, percebe-se que a circulação de determinado pensamento educacional, através da formação pedagógica a partir de autores como Paulo Freire, atuou no sentido de transformar as práticas de tais docentes e de pensar e instituição educacional como um espaço de mudança social.

Aliado ao acesso a determinados teóricos, cujo os conteúdos de suas obras contribuíram diretamente para a conscientização da atual condição de trabalho e o papel social não só dos professores, mas também para os movimentos sociais, notadamente a organização dos professores enquanto profissionais da educação que detém direitos, e que tem um papel fundamental na formação e construção de uma sociedade mais democrática, culminando com as greves do magistério, as quais corroboraram para a compreensão do magistério como classe.

\section{Referências}

Alberti, V. (2005). Manual de História Oral. Rio de Janeiro: FGV.

Amado, J. (1995). O grande mentiroso: tradição, veracidade e imaginação em História Oral. História, São Paulo, n, 14, p. 125-136.

Araújo, J. A. (2010) A USAID, o regime militar e a implantação das escolas polivalentes no Brasil. Revista de Epistemologia y Ciencias Humanas, Rosário Argentina, n. 2, 11p. 
Aristóteles. (2017). A Política. (N. S., Chaves Trad.). Rio de Janeiro: Nova Fronteira. Ciavatta, M. (2015). O trabalho docente e os caminhos do conhecimento: a historicidade da Educação Profissional. Rio de Janeiro: Lamparina.

Ciavatta, M. (2007). Memória e temporalidade do trabalho e da educação. Rio de Janeiro: Lamparina, FAPERJ.

Ferreira, M. M.; Amado, J. (Org.) (1998). Usos e abusos da História oral. Rio de Janeiro: Ed. FGV.

Félix, L. O. (1998). História e Memória: uma problemática de pesquisa. Passo Fundo: Universitária.

Magalhães, J. (2010). Da Cadeira ao Banco: Escola e Modernização (Séculos XVIII$X X)$. Lisboa: Educa \& Ui\&dCE.

Martiarena de Oliveira, M. A. (2018). Revista Polivisão: a imprensa pedagógica em uma escola polivalente. In: Hernández Diaz, J. M. (Ed.). La prensa pedagógica de Ios profesores. Salamanca: Ediciones Universidad de Salamanca, p.215-228.

Martiarena de Oliveira, M. A. (2017). Escola Maria Teresa Vilanova Castilhos Escola Polivalente: acervos fotográficos e História da Educação. RIDPHE_R Revista Iberoamericana do Patrimônio Histórico-Educativo, 3(2), 2017, p. 323-336. doi:https://doi.org/10.20888/ridphe_r.v3i2.7825

Shiroma, E. O.; Moraes, M. C. M. ; Evangelista, O. (2004). Política Educacional. 3. ed. Rio de Janeiro: DP\&A.

Souza, S.; Lima, G. (2016) Escolas Polivalentes na Ditadura Civil-Militar: Marco no Modelo de Ensino Profissionalizante ou Instrumentos de Propaganda do Regime? O Processo de Implantação do Polivalente de Ituiutaba- Mg (1974-1985). Educação \& Formação, 1(2), 2016, p. 72-88. doi:http://dx.doi.org/10.25053/edufor.v1i2.1892

Thomson, A. (1997). Recompondo a memória: questões sobre a relação entre a história oral e as memórias. Projeto História, São Paulo, n. 15, p. 52-84. 